\title{
Elderly as a High-risk Group during COVID-19 Pandemic: Effect of Circadian Misalignment, Sleep Dysregulation and Melatonin Administration
}

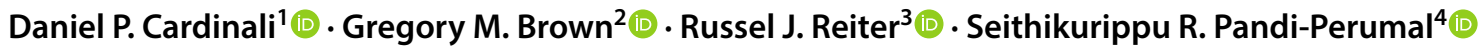

Received: 22 July 2020 / Revised: 1 September 2020 / Accepted: 17 September 2020 / Published online: 26 September 2020

(c) Springer Nature Singapore Pte Ltd. 2020

\begin{abstract}
The association of age with a higher vulnerability to COVID-19 infection is a subject of major importance. Several factors, including higher stress due to social isolation, diminished melatonin levels with age, and higher exposure of individuals to light at the evening, which reduces melatonin levels and disrupts circadian rhythmicity are relevant for maintaining the circadian health in aged individuals. Properly administered, chronotherapy restores the optimal circadian pattern of the sleep-wake cycle in the elderly. It involves adequate sleep hygiene, timed light exposure, and the use of a chronobiotic medication like melatonin, which affects the output phase of circadian rhythms thus controlling the biological clock. Besides, the therapeutic potential of melatonin as an agent to counteract the consequences of COVID-19 infections has been advocated due to its wide-ranging effects as an antioxidant, anti-inflammatory, and as an immunomodulatory agent, as well as to a possible antiviral action. This article discusses how chronotherapy may reverse the detrimental circadian condition of the elderly in the COVID-19 pandemic.
\end{abstract}

Keywords Aging $\cdot$ Chronotherapy $\cdot$ Circadian rhythms $\cdot$ COVID-19 pandemic $\cdot$ Melatonin $\cdot$ Sleep-wake cycle $\cdot$ Social isolation

Daniel P. Cardinali

daniel_cardinali@uca.edu.ar

Gregory M. Brown

gregory_brown@camh.ca; gbrownpn@gmail.com

Russel J. Reiter

reiter@uthscsa.edu

Seithikurippu R. Pandi-Perumal

pandiperuma12020@gmail.com

1 Faculty of Medical Sciences, Pontificia Universidad Católica Argentina, Av. Moreau de Justo 1300, 1007 Buenos Aires, Argentina

2 Department of Psychiatry, Centre for Addiction and Mental Health, University of Toronto, Toronto, ON M5T 1R8, Canada

3 Department of Cell Systems and Anatomy, UT Health San Antonio, San Antonio, TX, USA

4 Somnogen Canada Inc., College Street, Toronto, ON M6H 1C5, Canada

\section{Introduction}

Aging is the leading risk factor for a variety of chronic diseases, including cancer, metabolic, cardiovascular, and neurodegenerative diseases, which result in a poor quality of life and an increase in morbidity and mortality. Among several other comorbidities, the aged population is more prone to suffer from coronavirus infection and the association of aging with a higher vulnerability to COVID-19 infection is a subject of major importance $[1,2]$.

Several interrelated processes, such as circadian desynchronization, free radical-mediated damage, mitochondrial dysfunction, low degree of inflammation ("inflammaging"), and immunosenescence have been identified as major pathophysiological mechanisms in aging [3]. In the context of the COVID-19 pandemic, several factors, including higher stress due to social isolation, diminished melatonin levels with age, and higher exposure of individuals to light at night which reduces melatonin levels and disrupts circadian rhythmicity must be considered. Thus, maintenance of healthy circadian rhythms is a sensible goal to achieve in aged individuals. 
Although the elderly may have better coping abilities compared to adults [4, 5], increased stress and depression of socially isolated seniors lead to increased proinflammatory and decreased anti-viral immune responses [2]. Among the consequences of staying indoors during the forced lockdown period, disruption of circadian rhythmicity, in particular, of the sleep/wake cycle is highly frequent, and age-associated circadian misalignment prevails $[6,7]$. Dysregulation of circadian timing systems is thought to be involved in several medical and mental conditions in aged individuals including cardiovascular and neurodegenerative diseases [8,9]. Herein, we briefly discuss how chronotherapy may reverse the detrimental circadian condition of the elderly in the COVID-19 pandemic.

\section{The Aged Circadian Clock Network}

During aging, the role of the central circadian pacemaker, the hypothalamic suprachiasmatic nuclei (SCN), in synchronizing clocks in peripheral tissues is affected in several ways. For instance, the sensitivity for detecting and responding to light as a synchronizing cue is depressed in aged individuals because of reduced lens transmittance of light [10], a reduced number of intrinsically photoreceptive retinal ganglion cells that transmit the photic input to the SCN [11], and a functional decline in the SCN itself. The aged SCN contains fewer neurons that express the neurotransmitter vasoactive intestinal polypeptide [12], an important mediator of intercellular coupling between individual SCN neurons. Moreover, the SCN in older individuals show a reduction in the intercellular coupling between individual neurons [13] and a reduced number of synaptic terminals. Thus, the cumulative reductions in (a) sensitivity to photic input, (b) signal transmission, and (c) coupling within neural networks, leads to a functional decline of light responses in the aged SCN. Remarkably, functional deterioration of an SCN during aging greatly reduces longevity, while transplanting the SCN from young donors into old hamsters increases their lifespan by almost $20 \%$ [14]. Core clock gene expression in the $\mathrm{SCN}$ is affected during aging in a gene-specific manner and aged SCN neurons have reduced circadian amplitude of intracellular signaling [15]. These likely contribute to the aging-related dampening of the circadian SCN-dependent output.

Forced lockdown such as during the current pandemic disrupts timing and duration of exposure to ambient light, the most important environmental Zeitgeber [16]. The use of mobile phones, tablets, and computers to watch the news, binge-watching of web series, and connecting on social media leads to excessive screen time in evening hours [17]. The blue light emitted from screens suppresses the natural production of melatonin at night. Activity levels during the day also influence the sleep pattern; low levels of activity (whether due to confinement or depression) negatively affects sleep, as does strenuous activity (e.g. due to stress or work overload) $[18,19]$.

\section{Sleep Changes in the COVID-19 Pandemic}

Any stressful event, whether related to personal life or caused by natural disasters, precipitates sleep disturbances, particularly among people with greater vulnerability such as the elderly. Surveys in the general population indicate that insomnia, poor sleep, and poor sleep quality are widespread complaints in this pandemic [20]. The observed incidence is similar to that of major crises involving, for example, natural disasters such as earthquakes or floods. In particular, healthcare workers directly involved with patients diagnosed or at risk of COVID-19 have shown very high rates of insomnia [21, 22].

With the COVID-19 pandemic, at least two factors beyond stress are also involved: the effects of lockdown and atypical homework schedules. The current view of the physiological regulation of the circadian rhythm of sleep/ wakefulness (the main circadian rhythm in the body) holds that it is regulated by two components, namely, a circadian ( $24 \mathrm{~h}$ ) component and a homeostatic component [23]. The circadian time system, is controlled by exposure to daylight and various social and environmental synchronizers, such as daily routines like getting up at a specific time, eat, exercise or participate in social and leisure activities. In confined conditions, several of these time signals are altered as there are fewer restrictions on performing these activities at fixed times.

Furthermore, as exposure to daylight is the main factor regulating the circadian time system, restricting its exposure affects circadian time. It should be noted that natural sunlight is the main environmental time signal that regulates the circadian clock, allowing physiological functions to occur at optimal times of the day [24]. During the day, the intensity of outdoor light can reach 100,000 lx in direct sunlight and typically $\sim 25,000 \mathrm{~lx}$ in broad daylight, while the intensity of light in closed rooms with artificial lighting is considerably lower, i.e. 200-300 lx [25]. Therefore, spending much of the day in low light conditions, indoors only, can have detrimental effects via a number of factors. First, the architecture of many buildings is not designed for the specific needs of healthy people during the day. Second, artificial lighting systems have only been installed to meet the needs of the human visual system, not the circadian system. Third, sufficient light each morning upon awakening advances the synchronization of the circadian clock each day to keep biological functions in sync with the solar day. 


\section{Sleep Alteration During Aging}

Melatonin plays a major role in the circadian component that regulates the timing of sleep onset. The circadian rhythm in synthesis and secretion of pineal melatonin is closely associated with the sleep rhythm in both normal and blind subjects [26]. The onset of nighttime melatonin secretion is initiated approximately $2 \mathrm{~h}$ in advance of an individual's habitual bedtime and has been shown to correlate with the onset of evening sleepiness. Several studies implicate endogenous melatonin in the physiological regulation of the circadian mechanisms governing sleep propensity [27, 28]. Aging often is associated with a significant reduction in sleep efficiency and continuity and coincides with a significant reduction in amplitude of the melatonin rhythm and consequently of many other circadian rhythms as well [29]. An increase in early morning awakenings and difficulty in falling sleep have been frequently reported in the elderly. Impaired melatonin secretion is associated with sleep disorders that are encountered in elderly insomniacs. Indeed, aging may be a process resulting from the relative circadian desynchrony produced by melatonin deficiency and melatonin can be effective for improving the quality of life in the elderly via its recognized chronobiotic capacity [30].

\section{Melatonin and Immune Changes in Aging}

Advanced age is characterized by a progressive decreasing amplitude and phase advance of circadian rhythmicity in overall biological functions including blood pressure, hormonal circadian secretions, and changes in immune function [31], as well as by enhanced fibrotic processes, with subsequent sclerosis of the vascular system, liver, and kidney [32]. The decrease in circulating melatonin levels has been advocated as responsible for these changes [30,33]

Concerning immune regulation, the main age-related variations in immune system activity consist of a decline in T helper (Th) 1 and T regulatory ( $\mathrm{T} \mathrm{reg}$ ) cell counts [34] in association with an increase in Th17 cell number [35]. The rise in Th17 cells together with a decline in $\mathrm{T}$ reg cell function predispose to autoimmune diseases. On the other hand, the decline in Th1 lymphocytes in association with an increase in Th17 cell count predispose to cancer [36].

Age-related immune changes probably represent the main biological mechanism responsible for the enhanced frequency of systemic human diseases in the elderly, including tumors, autoimmune pathologies, and atherosclerosis-related cardiovascular disorders. Indeed, recent advances in understanding immune functions have demonstrated that the immune system is not only involved in the defense against cancer and infections, but also in the regulation of most biological systems, including cardiovascular, nervous and endocrine systems [37]. An example of this is given by the angiotensin-converting enzymes (ACE) and ACE2, whose activations are responsible for hypertensive/inflammatory effects and hypotensive/anti-inflammatory actions, respectively [38]. Aging is characterized by a progressive increase in ACE / ACE2 ratio, presumably due to decreased melatonin levels since melatonin inhibits ACE and promotes ACE2 expression [39-44].

The pathophysiology of COVID-19 involves the binding of the coronavirus to ACE2, which is expressed in airway epithelial cells including those of the alveolar sac as well as in other tissues like the intestinal epithelial cells [45]. Two subunits of the $\mathrm{S}$ spike protein, $\mathrm{S} 1$ and $\mathrm{S} 2$, of the virus, are involved in this reaction; S1 attaches to ACE2 and S2 mediates the fusion of the virus with the cell membrane. After that, the viral RNA is released into the cytoplasm leading to the translation of two proteins forming a replication/ transcription complex that synthesizes new RNA encoding additional proteins. Once new genomic RNA is formed, it assembles with nucleocapsid proteins and glycoproteins yielding new viral particles [45].

Young people do not suffer from COVID-19 as frequently as do the elderly; among other possible reasons is that they usually have much higher circulating melatonin levels to prevent ACE2 downregulation and curtail the massive increase in inflammatory cytokines and reactive oxygen species, i.e., the cytokine storm. General immunity is impaired in severely compromised COVID-19 patients [46] and melatonin stimulates immunity [47]. Therefore, the use of melatonin, an endogenously-produced and proven-safe molecule, in adequate doses may prevent the development of severe disease symptoms in coronavirus patients [48]

\section{Chronotherapy}

The common causes of sleep disturbance during aging include, but are not limited to, lifestyle (e.g., retirement life), pre-existing medical and mental illnesses, polypharmacy, poor sleep habits, pre-existing sleep disorders, and psychological distress [49]. Sleep dysfunctions and sleep disorders are highly prevalent in the aging population [50]. As mentioned above, sleep disruption has become more prevalent during the COVID-19 pandemic.

The objective of chronotherapy is to optimize medical treatments taking into account the body's circadian rhythms [51, 52]. Chronotherapy works via two means: (1) it alters the sleep/wake rhythms of patients to improve the sequels of several pathologies; (2) it takes into account the 
circadian rhythms of patients to improve therapeutics. Both approaches are relevant for the discussion of chronotherapeutic strategies in aged individuals during the COVID-19 pandemic.

Even minor dysfunctions of the biological clock can greatly affect sleep/wake physiology. It may cause excessive diurnal somnolence, increase in sleep onset latency, phase delays or advances in sleep onset, frequent night awakenings, reduced sleep efficiency or increased periodic leg movements [53]. Chronotherapy is designed to restore the proper circadian pattern of the sleep-wake cycle in the elderly, through adequate sleep hygiene, timed light exposure, and the use of a chronobiotic medication like melatonin, that affects the output phase of circadian rhythms thus controlling the clock (Fig. 1).

Concerning the second basis of chronotherapy, it should be stressed that the immune system displays very strong circadian rhythmicity [54]. At the beginning of daily activity, there is increased expression of pro-inflammatory mediators such as interleukin (IL)-1 $\beta$, IL-6, and IL-12, as well as macrophage and leukocyte activity, which leads to potential damage to tissues. By contrast, anti-inflammatory mediators and other growth or angiogenesis factors peak during the resting phase (for ref. see [55]. Both CD4 and CD8 T cells activities against viral antigens reach their highest levels during the resting phase while the cytotoxic activity of natural killer cells is most severe at the beginning of the active part of the day. Indeed, the time of the day in which a viral infection occurs affects survival. For instance, infections at the beginning of the activity phase are more fatal than infections that occur at the beginning of the resting phase [56]. These temporal patterns may be disrupted in aged individuals, and thus circadian disorganization should be taken into account when using immune modulators and anti-inflammatory

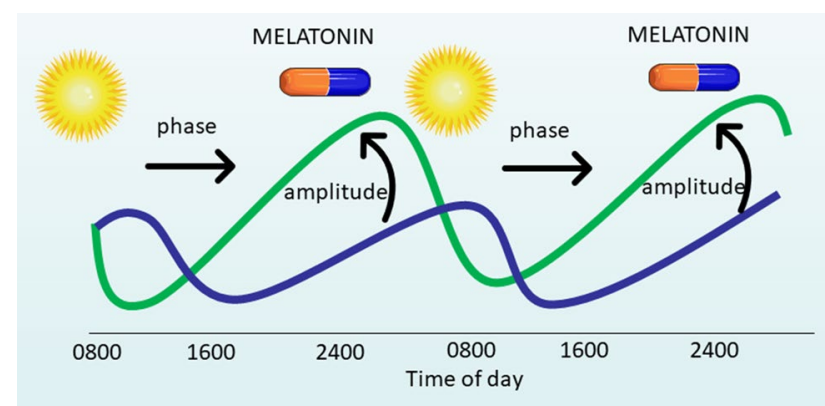

Fig. 1 Chronobiotic activity of melatonin. The combined use of melatonin and bright light to augment the amplitude and synchronize endogenous circadian rhythmicity in aging. Bright light in the morning together with melatonin at bedtime interact to augment the amplitude of sleep/wake cycle and other circadian rhythms. In delayed phase sleep syndrome melatonin augments the amplitude and phaseadvanced the sleep/wake rhythm agents in the older population [55]. It is plausible that proper circadian timing of anti-inflammatory drugs (chronotherapy) can target the detrimental inflammatory cascade in COVID19 patients without interfering with the fight of the immune system against the virus [57]. This can be extremely important for low dose dexamethasone treatment, given the recent demonstration that it may reduce to one-third mortality in severely-infected COVID-19 patients [58].

\section{Conclusion}

Melatonin is the prototype of the drugs that influence the circadian apparatus (i.e. chronobiotics) [59] and plays a major function in the coordination of circadian rhythmicity. Moreover, melatonin is a potent cytoprotective agent having strong antioxidant, anti-inflammatory, and immunoregulatory activity. In the context of the COVID-19 pandemic, the therapeutic potential of melatonin as an agent to counteract the consequences of COVID-19 infections due to its wideranging effects as an antioxidant, anti-inflammatory, and immunostimulant, as well as to a possible antiviral action has been advocated. This subject has been extensively reviewed elsewhere [60-63]. In light of the public health problem triggered by the spread of COVID-19 and in the face of essentially null options for prevention or treatment presently available, the use of melatonin has been proposed to possibly control the consequences of this serious disease. A preliminary report supports this effect [64]. Based on the safety of melatonin, and to maximize its therapeutic efficacy, doses in the order of 50-100 mg p.o. have been proposed for prevention in vulnerable individuals, like the elderly.

At this time of compulsory and massive isolation or quarantine of aged people, they become particularly prone to circadian misalignment [65] and may benefit from receiving a chronobiotic compound as melatonin to maintain an adequate sleep/wake cycle and other circadian rhythms. Even at the high doses of melatonin employed and the use of a fast release preparation given at a single time point in the day (bedtime) retains the chronobiotic effects (Fig. 2). Therefore, the rationale for the use of melatonin as a preventive medication in the COVID-19 pandemic focuses not only on the attenuation of the immunoinflammatory disorder but also on general improvement and prevention of possible complications provided by the maintenance of optimal circadian rhythmicity.

As of today, there is no single effective treatment available for COVID-19; however, several anti-inflammatory and antiviral molecules are being tested and administered. Different vaccines are in various stages of development. Although the peak of SARS-CoV-2 pandemic appears to be passing a new wave is already occurring in some 
Fig. 2 Because of its pharmacokinetic properties. i.e., a very short half-life in the blood, when melatonin is given orally as a fast release preparation at bedtime, melatonin gives rise to a chronobiotic signal regardless of the amounts given

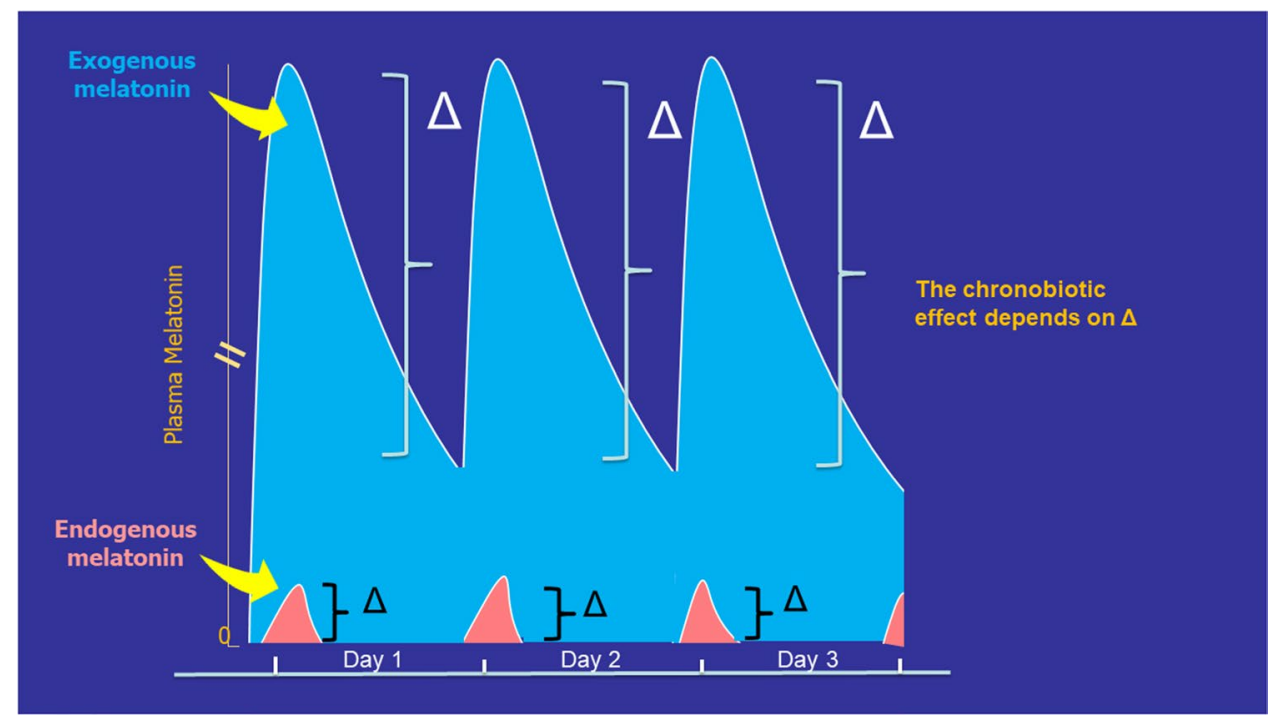

regions. Moreover SARS-CoV-2 may never disappear totally. Thus, identifying an effective treatment of COVID19 is mandatory.

Acknowledgements This research did not receive a specific grant from funding agencies in the public, commercial, or not-for-profit sectors.

\section{Compliance with ethical standards}

Conflict of interest The authors have read the journal's policy and have the following potential conflicts: SRP is a stockholder and the President and Chief Executive Officer of Somnogen Canada Inc., a Canadian Corporation. He declares that he has no competing interests that might be perceived to influence the content of this article. This does not alter the authors' adherence to all the journal policies. All remaining authors declare that they have no proprietary, financial, professional, nor any other personal interest of any nature or kind in any product or services and/or company that could be construed or considered to be a potential conflict of interest that might have influenced the views expressed in this manuscript.

Studies with human participants or animals This article does not contain any studies with human participants or animals performed by any of the authors. No primary data have been reported.

\section{References}

1. Esteve A, Permanyer I, Boertien D, Vaupel JW. National age and coresidence patterns shape COVID-19 vulnerability. Proc Natl Acad Sci USA. 2020;2020:117. https://doi.org/10.1073/ pnas. 2008764117.

2. Perrotta F, Corbi G, Mazzeo G, Boccia M, Aronne L, D'Agnano V, et al. COVID-19 and the elderly: insights into pathogenesis and clinical decision-making. Aging Clin Exp Res. 2020. https://doi. org/10.1007/s40520-020-01631-y.

3. Welz PS, Benitah SA. Molecular connections between circadian clocks and aging. J Mol Biol. 2020;2020:432. https://doi. org/10.1016/j.jmb.2019.12.036.
4. Courtin E, Knapp M. Social isolation, loneliness and health in old age: a scoping review. Health Soc. Care Commun. 2017;25:799-812. https://doi.org/10.1111/hsc.12311.

5. Grover S, Avasthi A, Sahoo S, Lakdawala B, Dan A, Nebhinani $\mathrm{N}$, et al. Stigma experienced by patients with severe mental disorders: a nationwide multicentric study from India. Psychiatry Res. 2017;257:550-8. https://doi.org/10.1016/j.psych res.2017.08.027.

6. Tähkämö L, Partonen T, Pesonen A-K. Systematic review of light exposure impact on human circadian rhythm. Chronobiol Int. 2019;36:151-70. https://doi.org/10.1080/07420 528.2018.1527773.

7. Altena E, Baglioni C, Espie CA, Ellis J, Gavriloff D, Holzinger $B$, et al. Dealing with sleep problems during home confinement due to the COVID-19 outbreak: practical recommendations from a task force of the European CBT-I Academy. J Sleep Res. 2020;2020:13052. https://doi.org/10.1111/jsr.13052.

8. Chellappa SL, Vujovic N, Williams JS, Scheer FAJL. impact of circadian disruption on cardiovascular function and disease. Trends Endocrinol Metab. 2019;30:767-79. https://doi. org/10.1016/j.tem.2019.07.008.

9. Foster RG. Sleep, circadian rhythms and health. Interface Focus. 2020;2020:10. https://doi.org/10.1098/rsfs.2019.0098.

10. Kessel L, Lundeman JH, Herbst K, Andersen TV, Larsen M. Agerelated changes in the transmission properties of the human lens and their relevance to circadian entrainment. J Cataract Refract Surg. 2010;36:308-12. https://doi.org/10.1016/j.jcrs.2009.08.035.

11. Lupi D, Semo M, Foster RG. Impact of age and retinal degeneration on the light input to circadian brain structures. Neurobiol Aging. 2012;33:383-92. https://doi.org/10.1016/j.neurobiola ging.2010.03.006.

12. Krajnak K, Kashon ML, Rosewell KL, Wise PM. Aging alters the rhythmic expression of vasoactive intestinal polypeptide mRNA but not arginine vasopressin mRNA in the suprachiasmatic nuclei of female rats. J Neurosci. 1998;18:4767-74. https ://doi.org/10.1523/jneurosci.18-12-04767.1998.

13. Nakamura TJ, Nakamura W, Tokuda IT, Ishikawa T, Kudo T, Colwell CS, Block GD. Age-related changes in the circadian system unmasked by constant conditions. ENeuro. 2015;2015:2. https://doi.org/10.1523/ENEURO.0064-15.2015.

14. Hurd MW, Ralph MR. The Significance of circadian organization for longevity in the golden hamster. J Biol Rhythms. 1998;13:430-6. https://doi.org/10.1177/074873098129000255. 
15. Zhao J, Warman GR, Cheeseman JF. The functional changes of the circadian system organization in aging. Ageing Res Rev. 2019;52:64-71.

16. Finger AM, Kramer A. Mammalian circadian systems: organization and modern life challenges. Acta Physiol (Oxf). 2020. https ://doi.org/10.1111/apha.13548.

17. Morin CM, Carrier J, Bastien C, Godbout R. Sleep and circadian rhythm in response to the COVID-19 pandemic. Can J Public Health. 2020;2020:1-4. https://doi.org/10.17269/s4199 7-020-00382-7.

18. Gulia KK, Kumar VM. Importance of Sleep for Health and Wellbeing Amidst COVID-19 Pandemic. Sleep Vigil. 2020;4:49-50. https://doi.org/10.1007/s41782-020-00087-4.

19. Jawaid A. Protecting older adults during social distancing. Science. 2020;2020(80-368):145. https://doi.org/10.1126/scien ce.abb7885.

20. Cellini N, Canale N, Mioni G, Costa S. Changes in sleep pattern, sense of time and digital media use during COVID-19 lockdown in Italy. J Sleep Res. 2020;15:e13074. https://doi. org/10.1111/jsr.13074.

21. Ferini-Strambi L, Zucconi M, Casoni F, Salsone M. COVID-19 and sleep in medical staff: reflections, clinical evidences, and perspectives. Curr Treat Options Neurol. 2020;22(10):29. https ://doi.org/10.1007/s11940-020-00642-4.

22. McFee RB. COVID-19 mental health considerations for health care workers and patients: a brief overview. Dis Mon. 2020;25:101061. https://doi.org/10.1016/j.disam onth.2020.101061.

23. Borbély AA, Daan S, Wirz-Justice A, Deboer T. The twoprocess model of sleep regulation: a reappraisal. J Sleep Res. 2016;25:131-43. https://doi.org/10.1111/jsr.12371.

24. Wright KP Jr, McHill AW, Birks BR, Griffin BR, Rusterholz T. Chinoy ED Entrainment of the human circadian clock to the natural light-dark cycle. Curr Biol. 2013;23:1554-8. https://doi. org/10.1016/j.cub.2013.06.039.

25. Spitschan M, Aguirre GK, Brainard DH, Sweeney AM. Variation of outdoor illumination as a function of solar elevation and light pollution. Sci Rep. 2016;6:26756. https://doi.org/10.1038/ srep26756.

26. Emens JS, Eastman CI. Diagnosis and treatment of non-24-h sleep-wake disorder in the blind. Drugs. 2017;77:637-50. https ://doi.org/10.1007/s40265-017-0707-3.

27. Auld F, Maschauer EL, Morrison I, Skene DJ, Riha RL. Evidence for the efficacy of melatonin in the treatment of primary adult sleep disorders. Sleep Med Rev. 2017;34:10-22. https:// doi.org/10.1016/j.smrv.2016.06.005.

28. Gobbi G, Comai S. Sleep well. Untangling the role of melatonin MT1 and MT2 receptors in sleep. J Pineal Res. 2019;2019:66. https://doi.org/10.1111/jpi.12544.

29. Duffy JF, Zitting KM, Chinoy ED. Aging and circadian rhythms. Sleep Med Clin. 2015;10:423-34. https://doi.org/10.1016/j. jsmc.2015.08.002.

30. Cardinali DP. Melatonin as a chronobiotic/cytoprotector: its role in healthy aging. Biol Rhythm Res. 2019;2019:50. https://doi. org/10.1080/09291016.2018.1491200.

31. Lananna BV, Musiek ES. The wrinkling of time: aging, inflammation, oxidative stress, and the circadian clock in neurodegeneration. Neurobiol Dis. 2020;2020:139. https://doi. org/10.1016/j.nbd.2020.104832.

32. Rockey DC, Darwin Bell P, Hill JA. Fibrosis-a common pathway to organ injury and failure. N Engl J Med. 2015;372:113849. https://doi.org/10.1056/NEJMra1300575.

33. Hardeland R. Melatonin and the theories of aging: a critical appraisal of melatonin's role in antiaging mechanisms. J Pineal Res. 2013;55:325-56. https://doi.org/10.1111/jpi.12090.
34. Hwang KA, Kim HR, Kang I. Aging and human CD4+ regulatory T cells. Mech Ageing Dev. 2009;130:509-17. https://doi. org/10.1016/j.mad.2009.06.003.

35. Tesar BM, Du W, Shirali AC, Walker WE, Shen H, Goldstein DR. Aging augments IL-17 T-cell alloimmune responses. Am J Transplant. 2009;9:54-63. https://doi.org/10.111 1/j.1600-6143.2008.02458.x.

36. Lissoni P, Rovelli F, Vigorè L, Messina G, Lissoni A, Porro G, Di Fede G. How to monitor the neuroimmune biological response in patients affected by immune alteration-related systemic diseases. In: Methods Mol Biol. Humana Press Inc., 2018: pp. 171-91. https://doi.org/10.1007/978-1-4939-7828-1_10

37. Arendse LB, Jan Danser AH, Poglitsch M, Touyz RM, Burnett JC, Llorens-Cortes $\mathrm{C}$, et al. Novel therapeutic approaches targeting the renin-angiotensin system and associated peptides in hypertension and heart failure. Pharmacol Rev. 2019;71:539-70. https:// doi.org/10.1124/pr.118.017129.

38. Santos RAS, Oudit GY, Verano-Braga T, Canta G, Steckelings UM, Bader M. The renin-angiotensin system: Going beyond the classical paradigms. Am J Physiol Hear Circ Physiol. 2019;316:H958-H970970. https://doi.org/10.1152/ajpheart.00723 .2018 .

39. Ishigaki $\mathrm{S}$, Ohashi $\mathrm{N}$, Matsuyama $\mathrm{T}$, Isobe $\mathrm{S}$, Tsuji $\mathrm{N}$, Iwakura $\mathrm{T}$, et al. Melatonin ameliorates intrarenal renin-angiotensin system in a 5/6 nephrectomy rat model. Clin Exp Nephrol. 2018;22:539_ 49. https://doi.org/10.1007/s10157-017-1505-7.

40. Ji ZZ, Xu YC. Melatonin protects podocytes from angiotensin IIinduced injury in an in vitro diabetic nephropathy model. Mol Med Rep. 2016;14:920-6. https://doi.org/10.3892/mmr.2016.5313.

41. Kong J, Zhang Y, Liu A, Li H, Liu S, Wang J, et al. Melatonin attenuates angiotensin II-induced abdominal aortic aneurysm through the down-regulation of matrix metalloproteinases. Oncotarget. 2017;8:14283-93. https://doi.org/10.18632/oncotarget .15093.

42. Nakao T, Morita H, Maemura K, Amiya E, Inajima T, Saito Y, et al. Melatonin ameliorates angiotensin II-induced vascular endothelial damage via its antioxidative properties. J Pineal Res. 2013;55:287-93. https://doi.org/10.1111/jpi.12071.

43. Ohashi $\mathrm{N}$, Ishigaki S, Isobe $\mathrm{S}$. The pivotal role of melatonin in ameliorating chronic kidney disease by suppression of the reninangiotensin system in the kidney. Hypertens Res. 2019;42:761-8. https://doi.org/10.1038/s41440-018-0186-2.

44. Rahman A, Hasan AU, Kobori H. Melatonin in chronic kidney disease: a promising chronotherapy targeting the intrarenal reninangiotensin system. Hypertens Res. 2019;42:920-3. https://doi. org/10.1038/s41440-019-0223-9.

45. Cheng F, Rao S, Mehra R. COVID-19 treatment: Combining anti-inflammatory and antiviral therapeutics using a networkbased approach. Cleve Clin J Med. 2020. https://doi.org/10.3949/ ccjm.87a.ccc037.

46. Pence BD. Severe COVID-19 and aging: are monocytes the key? GeroScience. 2020. https://doi.org/10.1007/s11357-020-00213-0.

47. Tan DX, Hardeland R. Potential utility of melatonin in deadly infectious diseases related to the overreaction of innate immune response and destructive inflammation: focus on COVID-19. Melatonin Res. 2020;3:120-43. https://doi.org/10.32794/mr112 50052.

48. Zhang R, Wang X, Ni L, Di X, Ma B, Niu S, Liu C, Reiter RJ. COVID-19: Melatonin as a potential adjuvant treatment. Life Sci. 2020;2020:250. https://doi.org/10.1016/j.lfs.2020.117583.

49. Cornelissen G, Otsuka K. Chronobiology of aging: a mini-review. Gerontology. 2017;63:118-28. https://doi.org/10.1159/00045 0945.

50. Gulia KK, Kumar VM. Sleep disorders in the elderly: a growing challenge. Psychogeriatrics. 2018;18:155-65. https://doi. org/10.1111/psyg. 12319 . 
51. Cederroth CR, Albrecht U, Bass J, Brown SA, Dyhrfjeld-Johnsen $\mathrm{J}$, Gachon F, et al. Medicine in the fourth dimension. Cell Metab. 2019;30:238-50. https://doi.org/10.1016/j.cmet.2019.06.019.

52. Ballesta A, Innominato PF, Dallmann R, Rand DA, Lévi FA. Systems chronotherapeutics. Pharmacol Rev. 2017;69:161-99. https ://doi.org/10.1124/pr.116.013441.

53. Zaki NFW, Spence DW, BaHammam AS, Pandi-Perumal SR, Cardinali DP, Brown GM. Chronobiological theories of mood disorder. Eur Arch Psychiatry Clin Neurosci. 2018;268:107-18. https://doi.org/10.1007/s00406-017-0835-5.

54. Haspel JA, Anafi R, Brown MK, Cermakian N, Depner C, Desplats P, et al. Perfect timing: circadian rhythms, sleep, and immunityAn NIH workshop summary. JCI Insight. 2020;2020:5. https://doi. org/10.1172/jci.insight.131487.

55. Al-Waeli H, Nicolau B, Stone L, Abu-Nada L, Gao Q, Abdallah $\mathrm{M}$, et al. Chronotherapy of non-steroidal anti-inflammatory drugs may enhance postoperative recovery. Sci Rep. 2020;2020:10. https ://doi.org/10.1038/s41598-019-57215-y.

56. Sengupta S, Tang SY, Devine JC, Anderson ST, Nayak S, Zhang $\mathrm{SL}$, et al. Circadian control of lung inflammation in influenza infection. Nat Commun. 2019;2019:10. https://doi.org/10.1038/ s41467-019-11400-9.

57. Tamimi F, Abusamak M, Akkanti B, Chen Z, Yoo SH, KarmoutyQuintana H. The case for chronotherapy in COVID-19 induced acute respiratory distress syndrome (ARDS). Br J Pharmacol. 2020. https://doi.org/10.1111/bph.15140.

58. RECOVERY Collaborative Group, Horby P, Lim WS, Emberson JR, Mafham M, Bell JL, et al. Dexamethasone in hospitalized patients with Covid-19-preliminary report. N Engl J Med. 2020. https://doi.org/10.1056/NEJMoa2021436.

59. Dawson D, Armstrong SM. Chronobiotics-drugs that shift rhythms. Pharmacol Ther. 1996;69:15-36. https://doi. org/10.1016/0163-72589502020-9.
60. Anderson G, Reiter RJ. Melatonin: roles in influenza, Covid-19, and other viral infections. Rev Med Virol. 2020;2020:30. https:// doi.org/10.1002/rmv.2109.

61. Zhang R, Wang X, Ni L, Di X, Ma B, Niu S, et al. COVID19: Melatonin as a potential adjuvant treatment. Life Sci. 2020;2020:250. https://doi.org/10.1016/j.1fs.2020.117583.

62. Hardeland R, Tan D-X. Protection by melatonin in respiratory diseases: valuable information for the treatment of COVID-19. Melatonin Res. 2020;3:264-75. https://doi.org/10.32794/mr112 50061.

63. Reiter RJ, Abreu-Gonzalez P, Marik PE, Dominguez-Rodriguez A. Therapeutic algorithm for use of melatonin in patients with COVID-19. Front. Med. 2020;7:226. https://doi.org/10.3389/ fmed.2020.00226.

64. Castillo RR, Quizon GRA, Juco MJM, Roman ADE, De Leon DG, Punzalan FER, et al. Melatonin as adjuvant treatment for coronavirus disease 2019 pneumonia patients requiring hospitalization MAC-19 PRO: a case series. Melatonin Res. 2020;3:97-310. https ://doi.org/10.32794/mr11250063.

65. Gulia KK, Kumar VM. Reverse quarantine in Kerala: managing the 2019 novel coronavirus in a state with a relatively large elderly population. Psychogeriatrics. 2020. https://doi.org/10.1111/ psyg.12582.

Publisher's Note Springer Nature remains neutral with regard to jurisdictional claims in published maps and institutional affiliations. 